\title{
Counseling Parents About Child Feeding: a Qualitative Evaluation of French Healthcare and Childcare Professionals' Experiences and Their Perception of a Brochure Containing New Recommendations
}

\section{Sofia De Rosso}

Centre des Sciences du Goût et de l'Alimentation, AgroSup Dijon, CNRS, INRAE, Université Bourgogne Franche-Comté

Camille Riera-Navarro

Centre des Sciences du Goût et de l'Alimentation, AgroSup Dijon, CNRS, INRAE, Université Bourgogne Franche-Comté

\section{Pauline Ducrot}

Santé publique France, French national public health agency

\section{Camille Schwartz}

Centre des Sciences du Goût et de l'Alimentation, AgroSup Dijon, CNRS, INRAE, Université Bourgogne Franche-Comté

\section{Sophie Nicklaus ( $\square$ sophie.nicklaus@inrae.fr)}

Centre des Sciences du Goût et de l'Alimentation, AgroSup Dijon, CNRS, INRAE, Université Bourgogne Franche-Comté

\section{Research Article}

Keywords: feeding recommendations, guidelines, health communication, health promotion, complementary feeding, qualitative research, parental feeding practices, breastfeeding, public health, pediatricians

Posted Date: January 24th, 2022

DOI: https://doi.org/10.21203/rs.3.rs-1211201/v1

License: (c) (i) This work is licensed under a Creative Commons Attribution 4.0 International License. Read Full License 


\section{Abstract}

Background: Parents are crucial in establishing their children's eating habits, and healthcare (HCPs) and childcare professionals (CCPs) can provide meaningful and trusted guidance on feeding, especially in the 0-3-year-old period. With the upcoming release of the official brochure containing the new child feeding recommendations in France, this study aims to: 1) assess professionals' practices and perceptions regarding their communication with parents on child feeding and 2) evaluate their impressions of the new brochure.

Methods: A 15-page brochure containing updated child feeding recommendations for children 0-3 years old was developed by the French public health agency. Online semi-structured interviews were conducted with professionals $(n=21)$, including 13 pediatricians and general practitioners (HCPs), nine childcare assistants or professionals (CCPs) two weeks after they were provided with this brochure to read. The interview guide was developed and piloted with other professionals $(n=3)$ prior to these interviews. Interview data were transcribed verbatim and analyzed thematically using an inductive approach.

Results: While HCPs and CCPs mostly communicate orally with parents, both acknowledged that the brochure might be a helpful supplement, especially for CCPs to legitimize their advice to parents. For HCPs, giving the brochure to parents may help provide systematic advice and save time during consultations. Professionals serving parents of lower socioeconomic status would prefer a supplement with less text and more illustrations. In general, the messages were perceived to be easily understandable but providing detachable cards to distribute according to the child's age would facilitate information dissemination and might be more useful to parents. Professionals reported that lack of training, the circulation of contradictory information, and language barriers were common challenges. Professionals suggested that short texts with more references and visual aids could improve the brochure.

Conclusions: French professionals welcome the new official brochure as a means to spread updated child feeding recommendations, but it could be modified to be better adapted to their needs of communication with parents and to facilitate the relay of information. Providing updated and consistent information to parents should be considered a priority for public health stakeholders toward increased adherence to new recommendations.

\section{Background}

The first thousand days of life from conception constitute a crucial period in child development; in fact, this stage is characterized by rapid growth in terms of physical evolution and behavior establishment (1). Interventions targeting early childhood provide a unique window of opportunity to establish optimal infant nutrition and healthy eating behaviors $(2,3)$. Moreover, promoting healthy lifestyles from infancy is paramount for the prevention of chronic conditions such as childhood obesity, of which the increasing prevalence in developed and developing countries is growing into a significant global health concern (4). Childhood obesity, in addition to being a strong risk factor for adult overweight or obesity (5), is 
associated with an increased risk of comorbidities throughout life, including the development of diabetes, certain forms of cancer, premature all-cause and cause-specific mortality, and cardiovascular diseases (6-8).

Diet and physical activity are factors directly associated with the development of overweight and obesity $(9,10)$. These factors are linked to behaviors that are sensitive to the effects of the different environmental stimuli that influence child development during early life, as shown by Bronfenbrenner's ecological systems theory (11). Among the external components that could affect children, parents play a decisive role in shaping the eating behaviors of their offspring, among other behaviors (12). For example, parents could modify children's food regulation capacities (13-15). Lack of responsiveness in parentchild interaction during meal times could impair the ability of the child to adjust his or her energy intake, often resulting in accelerated weight gain (16-18). Parental feeding practices related to introducing vegetable are also likely to influence how much children like these foods (19). Addressing lifestyle behaviors and feeding practices with parents early in children's lives could help in the prevention of chronic diseases such as obesity and its health-related consequences $(20,21)$. Public policies, for child feeding in this case, should account for the latest scientific contributions when addressing public health initiatives aimed at shifting the management of health education of the population toward evidencebased best practices $(22,23)$.

Parents might worry about not knowing how to behave to establish healthy diet habits for their children, which can drive them to search for any kind of advice about feeding. The need for guidance might alter parents' ability to look for factual information (24). Parents seek information about child feeding from many different sources, including the internet, media, books and magazines, family, friends, and health and childcare professionals $(25,26)$. The nature of the information conveyed by these different sources can vary widely, and the content of information can even be contradictory (27), resulting in the spread of disinformation and misinformation. Considering that early eating habits generally have a lasting impact throughout childhood and continue into adulthood (28), it is essential to support parents with the appropriate tools and guide them to promote the healthy development of children. In France, official recommendations for feeding children aged zero to three were updated and published in $2019(29,30)$. A paper brochure intended for parents and professionals was produced by the French public health agency to make the recommendations relating to infant and young child feeding as accessible as possible to parents. From a public health perspective, a precise and systematic evaluation of communication tools produced by policy-makers and public health stakeholders at the design stage is useful to account for the needs of public health intervention recipients. In the present case, these recipients are parents and professionals, who are judged by parents as a natural intermediary for the circulation of such information (31).

In France, when the child is between zero and sixteen years old, parents are encouraged to take her or him to 20 free and compulsory consultations with health care professionals (HCPs), and the majority of visits (13 visits) take place within the first three years of life (32). Therefore, health and childcare professionals (CCPs) play an important role in France for the support of harmonious child development: they interact 
with parents during the different phases of child feeding, and they are well placed to positively influence parenting decisions. The majority of parents in France trust pediatricians; as the 2013 Nutri-Bébé study showed, $58 \%$ of mothers of children between 15 days and 35 months seek advice to feed their child (33). Moreover, a recent study explored French parents' information-seeking behaviors on infant and young child feeding. In terms of influence on parental feeding practices, HCPs are the most used and trusted source of advice (primary source of information for $81 \%$ of parents with a level of influence of $7.7 \pm$ $1.7 / 10$ ), followed by CCPs (influence $7.3 \pm 1.8$, but less used, $30 \%$ ) (31). For these reasons, it is relevant to address HCPs' and CCPs' perceptions of public health material to support parental feeding decisions.

Interventions given via HCPs have an impact on obesity prevention, as shown by quantitative and qualitative studies (34-36). However, little research has been conducted on understanding professionals' practices and needs and integrating those needs to design effective prevention material for feeding children aged zero to three years. This material could be used to efficiently disseminate relevant messages and up-to-date information about child feeding to parents. Thus, the main objectives of this study were: (1) to investigate, via semi-structured interviews, the practices and needs of HCPs and CCPs when giving guidance to parents on child feeding (zero to three years old) and (2) to explore the first impressions of professionals on the brochure produced by the French public health agency, together with their level of understanding and acceptance of the new recommendations.

\section{Methods}

\section{Spreading child feeding recommendations via the mean of a brochure targeting parents}

In France, there was a recent update of official guidelines for feeding children aged zero to three years, which were published by the French national agency for Food, Environmental and Occupational Health Safety (ANSES) in 2019 (29). The process was supervised by the Ministry of Health, and in October 2020, the High Council of Public Health released a report reflecting these benchmarks (30). The main changes in the new recommendations (tested with this study) compared to the previous recommendations (37) are summarized in Table 1. Subsequently, in 2019-2020, the content for a paper brochure intended for parents was developed by the French public health agency (Santé publique France). Santé publique France organized a group of experts with the intent of designing material to make recommendations relating to feeding children aged zero to three years as accessible as possible to parents, who are the ultimate users of this communication strategy. The process of reformulating the recommendations and designing the brochure spanned November 2019 to July 2021, with the document becoming available to the general public in September 2021 (the version used in this study was one of the latest drafts).

The draft version of the brochure, comprising the core text without pictures or illustrations, was provided to the professionals interviewed in this study. The document contained 15 pages plus a table summarizing the recommendations based on the age of the child and for the quantities of each food group. The brochure consisted of eight chapters. The first three chapters addressed generic topics 
pertaining to the development of eating behaviors of children and good practices for parents (including responsive feeding, discovering textures, screen exposure); the remaining five chapters covered the development of feeding practices based on the age of the child.

Table 1

Previous (2004) vs. new (2021) recommendations on child feeding contained in the official public health material (brochure) released in France.

\begin{tabular}{|c|c|c|}
\hline Topic & Previous recommendation & New recommendation \\
\hline Start of CoF & After 6 months & Between 4 and 6 months \\
\hline $\begin{array}{l}\text { Introduction of all food } \\
\text { types }\end{array}$ & After 6 months & Between 4 and 6 months \\
\hline $\begin{array}{l}\text { Introduction of different } \\
\text { textures }\end{array}$ & After 6 months & Between 6 and 8 months \\
\hline $\begin{array}{l}\text { Introduction of pulses } \\
\text { and whole grain } \\
\text { starches }\end{array}$ & Between 15 and 18 months & Between 4 and 6 months \\
\hline $\begin{array}{l}\text { Introduction of } \\
\text { allergens (including } \\
\text { gluten) }\end{array}$ & After 12 months & Between 4 and 6 months \\
\hline $\begin{array}{l}\text { Alternance of follow-on } \\
\text { milk and full fat cow } \\
\text { milk }\end{array}$ & $\begin{array}{l}\text { Between } 1 \text { and } 3 \text { years, but } \\
\text { to prefer follow-on milk }\end{array}$ & After the child turns 1 year \\
\hline Baby-led weaning & / & $\begin{array}{l}\text { No recommendation but this topic is } \\
\text { addressed }\end{array}$ \\
\hline $\begin{array}{l}\text { Non-recommended } \\
\text { foods and beverages }\end{array}$ & $\begin{array}{l}\text { To limit, and not before } 7 \\
\text { months }\end{array}$ & $\begin{array}{l}\text { To limit, to be introduced as later as } \\
\text { possible }\end{array}$ \\
\hline Fat & Never before 6 months & From the start of CoF \\
\hline Responsive feeding & $\begin{array}{l}\text { Not really addressed, from } \\
6 / 8 \text { months trust baby's } \\
\text { appetite }\end{array}$ & $\begin{array}{l}\text { Trust the baby's appetite at all the ages; } \\
\text { examples of baby's hunger and satiety } \\
\text { cues }\end{array}$ \\
\hline
\end{tabular}

CoF: complementary feeding

${ }^{*}$ E.g.: plant-based alternatives to formula, sugar sweetened beverages and foods, coffee, tea.

\section{Study design}

Healthcare and childcare professionals' experiences with communication with parents about child feeding were undertaken using a qualitative inductive approach (38). Face-to-face, semi-structured interviews were considered the best methodology to address the aim of the study, as they could allow us to address specific questions in line with the research aims, but they could still give the freedom to the participant to freely talk about his or her experiences (39). Given the context of the COVID-19 pandemic, 
interviews were scheduled online and conducted via videoconference when possible. In this way, it was easier to access participants in distant and different geographical locations, which allowed us to interview professionals from all over France (40). Moreover, the advantage of seeing the person and capturing the body language of participants was maintained and could allow researchers to make considerations on that, if needed. Written notes were taken after each interview to determine whether the interviewer deemed it necessary to highlight the attitudes or reactions of participants. The consequences of the restrictions imposed by COVID-19 health management on professionals' practices and their interactions with parents (doing medical appointments via video or phone calls) were also assessed in this study but will not be discussed in the present article. The consolidated criteria for reporting qualitative research (COREQ) checklist was applied to the description of methods and results (41).

\section{Participant recruitment}

In a previous quantitative study exploring the sources of parental information on child feeding in France, it was highlighted that HCPs and CCPs are the most influential sources of advice on child feeding for parents (31). Following what emerged in that study, we aimed to recruit a sample composed of two-thirds of HCPs, including pediatricians, general practitioners (GPs), and physicians working in maternal and child protection (PMI centers: protection maternelle infantile), and one-third of CCPs, including professionals working in childcare centers, childcare assistants, and nurses working in PMI centers. Professionals were eligible for the study if they were older than 18 years of age, practicing in France, and regularly interacting with young children (and consequentially their parents) as part of their professional practice. Retired professionals were excluded. To recruit participants, a purposive sampling method was initially used to ensure sample variety diversification: gender and age, profession and duration of professional experience, whether the participant has children, working in rural, urban, or semi-urban areas, and poverty rate of the working area. The objective was not to reach any quotas but rather to obtain a sample that was as balanced and diverse as possible. This initial method of recruitment was based on random calls or emails to HCPs and CCPs in departments that were pre-selected according to poverty and urbanization rates, $(42,43)$ to include participants who dealt with parents of different socioeconomic status. As per the protocol, if enough participants could not be recruited in due time, then we planned to use the snowball sampling method. Participants were also recruited by means of Facebook groups. Considering other qualitative studies interviewing healthcare professionals (44-46), 21 participants was considered sufficient to ensure a diverse sample to explore the objectives of this study. However, a possible data saturation effect was evaluated, i.e., the recruitment of participants would stop if new interviews did not provide any additional information. Recruitment and data collection took place simultaneously. The recruitment outcome was determined if further recruitment was needed to ensure representatives from different professional categories.

\section{Data collection}

Data collection took place in April and May 2021. An online demographic questionnaire was developed, and an informed consent form was also included. The link to complete the questionnaire and the informed consent were sent to those professionals whom, after first being contacted by the researchers 
(CRN or SDR) with a brief explanation of the study, volunteered to participate. No other links were established between researchers and participants before the study commenced. The eligibility questionnaire was sent to 118 professionals, of which 40 completed the questionnaire ( $25 \mathrm{HCPs}, 15$ CCPs), although one HCP was unreachable after having completed the eligibility questionnaire, and thus was not included in the study. After an eligibility check, the participants who corresponded to the required profiles were selected and included in the study $(n=21)$, and none of the included participants refused to participate in the study. Once the inclusion phase was completed, individual, semi-structured interviews were then scheduled for a date and time that suited the participants. The brochure was sent to participating professionals by email at least two weeks before the interview to allow adequate time to read it.

\section{Interview guide and interview procedure}

The interview guide was first developed based on data found in the literature (47) and then was tailored to the objectives of the study. This guide was checked by a reference group of public health stakeholders: three members of Santé publique France with backgrounds in nutrition and policy communication convened to advise the research team for the purposes of this study. This group worked on revising the brochure before national dissemination in September 2021. They reviewed and refined the study protocol and the interview guide. The interview guide was pilot tested with three preliminary interviews involving one HCP and two CCPs. A preliminary analysis of these interviews allowed modifications and refinements of the script and provided an estimate of the duration of interviews. This final version of the script ensured that the flow of the interviews could develop according to the research objectives. However, there was a margin of flexibility to enable participants to express their ideas and deepen their responses. The interview guide comprised three main topic sections: (1) perceptions and practices related to the communication needs of professionals about child feeding; (2) changes in communication with parents due to the COVID-19 health crisis; and (3) comprehension of a brochure intended for parents and acceptance of the new recommendations. For each section, there were several core questions and probes. The interview guide used for this study is presented in original language (French) as Additional file 1.

Semi-structured interviews took place in April and May 2021 in the professionals' native language (French). Interviews lasted an average of $54 \pm 9$ minutes. They were performed by the second author (CRN), a 25-year-old female, for the purpose of her thesis for her Master in Physiological and Psychological Food Choice Determinants. The interviewer had experience in health services research and engaging with HCPs as a result of her prior studies in medicine. The interviews were conducted either using a videoconference system (Skype for Business) or via telephone (two interviews). During the interviews, the participants were at their home $(n=18)$ or workplace $(n=3)$, and only the participant and the interviewer were present during the recording phase. At the beginning of each interview, CRN introduced herself (name and workplace) and gave a short introduction to the study and the data protection policy. The participants did not know anything else about the interviewer. Professionals had to verbally confirm that they agreed to be audio recorded. After being asked all the questions regarding the interview topics, professionals were invited to share any additional information that they considered important. When the 
participants had not read the brochure prior to the interview $(n=2)$, the interviewer gave them time to read it, either by postponing the interview or by calling for a break during the session, according to participant's preference. When there was nothing to add, participants were thanked for their time, and the following steps of the study were elucidated. The interviewer took some notes after each interview and had regular discussions with SDR, the PhD student (31-year-old female) with a background in public health and nutrition who oversaw this study and who contributed to the conception of the brochure and could participate in the previous phases of the brochure evaluation (e.g., focus groups with parents, evaluation of effect of the brochure on parental knowledge). All interviews were audio recorded and transcribed verbatim. After all the interviews concluded, the participants were sent a brief summary of the whole analysis (not a transcript) and were asked to refer to the researchers if they had anything to add or disprove. Participants did not provide additional feedback on the report to the researchers.

\section{Ethical consideration}

All the participants received a written description of the project and were informed of their right to withdraw at any time without prejudice. Professionals agreed to participate in the study by giving their informed consent and selecting the appropriate case in the online form. To ensure confidentiality of the information collected and anonymity, the participants were assigned a code that only the interviewer could match to their names. These codes were erased once the interviews were completed, and only sociodemographic characteristics were retained. Each participant received a voucher worth 40 Euros as a token of appreciation. Ethical approval $\left(n^{\circ} 21-788\right)$ for this study was obtained from the Institutional Review Board (IRB00003888, IORG0003254, FWA00005831) of the French Institute of Medical Research and Health. This study was registered by the data protection service involved.

\section{Data analysis}

The responses of the professionals were audio-recorded and transcribed verbatim by a professional transcription service (11/21 interviews) or by the interviewer (CRN) with the help of a research technician with experience in transcribing interviews. All verbatim data were double checked for accuracy by the interviewer and the first author (CRN and SDR). The software NVivo was used to analyze the interviews in their original language to avoid loss of meaning. A thematic analysis was conducted in accordance with the six steps proposed by Braun and Clarke (48): (1) data familiarization, (2) initial coding generation using a data-led approach, (3) searching for themes based on initial coding, (4) review of the themes, (5) themes final definition and labeling, and (6) report writing. The familiarization step was performed throughout the data collection phase by the first two authors (SDR, CRN), who both listened to recorded interviews and read the transcripts. The first author discussed with the interviewer on a regular basis during the interview phase to brainstorm about the themes based on emerging patterns (main ideas) in the data. The first three steps were performed manually and independently by SDR and CRN. Initially, eight interviews were selected for independent initial coding. Coding was performed with a data-led approach, with particular attention to include the topics addressed in the interview guide. At the completion of this coding phase, the emerging themes and subthemes were discussed with the other authors until a consensus was reached and a final coding scheme was created. The coding scheme was 
used to complete the coding of all the other interviews, which were coded independently by SDR and CRN. The final coding scheme was also used to readjust the initial coding of the first eight interviews. SDR and CRN subsequently compared the coding of all the interviews and evaluated whether there were doubts or difficulties regarding the placement of quotes. Then, a discussion took place until an agreement was reached, and all the codes were homogenized. At the end of this process, SDR and CRN once again reviewed the themes and subthemes and defined those that were relevant for answering the research questions of the current study. A final decision was made after discussion with SN. Data were analyzed in two parts: 1) discourse dealing with HCP and CCP practices and needs in terms of communication with parents about child feeding and 2) discourse dealing with their perception and impressions of the brochure and its evaluation.

\section{Results}

Table 2 summarizes the characteristics of the 21 participants. Interviews were undertaken with a total of $13 \mathrm{HCPs}$ (nine women) and eight CCPs (seven women) from a range of disciplines: five pediatricians, five general practitioners, and three PMI physicians (working in maternal and child protection centers) for a sub-total of $13 \mathrm{HCPs}$, and two childcare assistants, three professionals working in childcare centers, one childminder, and two PMI nurses, for a sub-title of eight CCPs. Eleven of the 21 professionals were aged 25-34 years (8/13 HCPs, 3/8 CCPs), eight were aged 35-49 years and two were aged 50-64 years. Fourteen professionals out of 21 (including 11/13 HCPs and 3/8 CCPs) had from zero to ten years of professional experience. Four professionals had 11-20 years of experience (1/13 HCP, 3/8 CCPs), two professionals had between 21 and 30 years of experience (one HCP, one CCP), and one CCP had over 30 years of experience. Fifteen professionals had children ( $8 / 13 \mathrm{HCPs}$ and $7 / 8 \mathrm{CCP})$. Nine out of the 21 professionals were working in areas with low poverty rates $(<13.3 \%)$, four in areas with high poverty rates $(>17.2 \%)$ and eight in areas with middle poverty rates (between 13.3\% and 17.2\%). Fourteen out of the 21 professionals were working in rural areas (urbanization rate over $80 \%$ ) and seven in semi urban areas (urbanization rate between $40 \%$ and $80 \%$ ).

\section{Table 2}

Characteristics of the sample of French professionals $(n=21)$. 


\begin{tabular}{|c|c|c|c|c|}
\hline Characteristics & & $\begin{array}{l}\text { All } \\
\text { (n) }\end{array}$ & $\begin{array}{l}\mathrm{HCPs}^{1} \\
\text { (n) }\end{array}$ & $\begin{array}{l}\mathrm{CCPs}^{2} \\
\text { (n) }\end{array}$ \\
\hline Totals & & 21 & 13 & 8 \\
\hline \multirow[t]{8}{*}{ Profession } & Pediatrician & 5 & 5 & I \\
\hline & General practitioner & 5 & 5 & l \\
\hline & PMI physician & 3 & 3 & l \\
\hline & Childcare assistant & 2 & / & 2 \\
\hline & $\begin{array}{l}\text { Professionals working in childcare } \\
\text { centers }\end{array}$ & 3 & / & 3 \\
\hline & Childminder & & & \\
\hline & PMI nurses & 1 & 1 & 1 \\
\hline & & 2 & l & 2 \\
\hline \multirow[t]{2}{*}{ Gender } & Female & 16 & 9 & 7 \\
\hline & Male & 5 & 4 & 1 \\
\hline \multirow[t]{3}{*}{ Age range } & Less than 35 years old & 11 & 8 & 3 \\
\hline & $35-49$ years old & 7 & 4 & 3 \\
\hline & More than 49 years old & 3 & 1 & 2 \\
\hline \multirow[t]{4}{*}{ Years of professional experience } & $0-10$ years & 14 & 11 & 3 \\
\hline & $11-20$ years & 4 & 1 & 3 \\
\hline & $21-30$ years & 2 & 1 & 1 \\
\hline & $>30$ years & 1 & / & 1 \\
\hline \multirow[t]{3}{*}{ Number of children } & 0 & 6 & 5 & 1 \\
\hline & 1 & 5 & 2 & 3 \\
\hline & 2 or more & 10 & 6 & 4 \\
\hline \multirow{3}{*}{$\begin{array}{l}\text { Poverty rate of the department } \\
(\%)^{*}\end{array}$} & $<13.3 \%$ & 9 & 6 & 3 \\
\hline & $13.3-17.2 \%$ & 8 & 5 & 3 \\
\hline & $>17.2 \%$ & 4 & 2 & 2 \\
\hline \multirow{2}{*}{$\begin{array}{l}\text { Urbanization rate of the } \\
\text { department (\%) }\end{array}$} & $40-80 \%$ & 7 & 4 & 3 \\
\hline & $>80 \%$ & 14 & 9 & 5 \\
\hline
\end{tabular}


${ }^{1}$ HCPs $=$ Healthcare professionals

${ }^{2}$ CCPs $=$ Childcare professionals.

*Poverty rate: the monetary poverty rate corresponds to the proportion of individuals (or households) in a given department in a situation of monetary poverty. An individual (or a household) is considered poor when he lives in a household with a standard of living below the poverty line. In France and in Europe, the threshold is most often set at $60 \%$ of the median standard of living.

Two main themes and nine subthemes were developed through the thematic analysis. The main themes were: 1) practices and needs in terms of communication with parents on child feeding, and 2) perceptions of the brochure. Regarding practices and needs, four subthemes were identified: communication practices, communication barriers between professionals and parents, needs of professionals and needs of parents to improve communication. Regarding perceptions of the brochure, subthemes included new recommendations, general impressions, suggestions to improve the brochure, perceptions of the utility of the brochure in HCP and CCP practices, and of the use that parents can make of it. Detected differences between HCPs' and CCPs' discourse were reported in the results. The themes and subthemes are illustrated in Table 3 and described in detail below.

Table 3

Overview of themes and subthemes.

\section{Themes}

1) Practices and needs in terms of communication with parents on child feeding

\section{Subthemes}

Communication practices

Communication barriers between professionals and parents

Needs of professionals to improve communication with parents

Needs of parents

2) Perceptions of the brochure
New recommendations

General impressions of the brochure (positive and negative)

Suggestions to improve the brochure

Perceptions of the utility of the brochure in $\mathrm{HCPs}$ and CCPs practice

Perceptions of the use that parents can have of the brochure 


\section{1) Practices and needs in terms of communication with parents on child feeding}

\section{Communication practices}

Professionals mentioned that they mostly provided information on child feeding orally to parents. HCPs also suggest websites to parents where they could search for information and the list of the most cited websites is reported in Table 4. HCPs explained that they systematically spoke with parents about child feeding at regular consultations within the first year of life, especially on complementary feeding (CoF) when the child is from four or five months of age. They mentioned that they do not have a rigid approach on how and when parents should start CoF. However, almost all HCPs reported that they liked to provide parents with a framework (starting with fruits and vegetables and introducing proteins after six months of age).

"So, I recommend starting at five months but only with vegetables, and then introducing fruits. After six months, introduce animal proteins such as meat, fish, and eggs." (P2, HCP, General practitioner)

HCPs mentioned that exchanges about child feeding become less frequent and less systematic after one year. The media used by HCPs to support oral communication are the child health record booklet, paper documents adapted to the child's age range, and websites that parents can visit (see Table 4).

Professionals working with the most disadvantaged families (especially in PMIs) explained using Google during consultations to show pictures on the computer screen and to translate their speech.

"We adapt to families, for example when we recommend whole milk, we put pictures on the computer, we say "the red cap", or "the pink cap" for follow-on milk; finally, we manage to find solutions." (P20, CCP, PMI nurse)

Regarding CCPs, very practical information on child feeding is exchanged with parents (what the child eats at home and at the childcare center), especially orally during the morning (when parents drop off their child) and evening "transmission" times (when parents pick up their child) but also with the support of paper documents. It was also reported that parents' meetings are occasionally organized in some childcare centers.

\section{Table 4}

Websites cited by HCPs (from top to bottom, the most to the least cited). 


\begin{tabular}{|l|}
\hline Websites \\
Mpedia.fr \\
Pediadoc.fr \\
MangerBouger.fr \\
Pédiatre-online.fr \\
Ameli.fr \\
Pap-pédiatrie.fr \\
Alimentationdutoutpetit.fr \\
\hline
\end{tabular}

\section{Communication barriers between professionals and parents}

Language was mentioned by professionals as a barrier to communication with parents, especially in PMIs, where professionals meet the most disadvantaged families (often with a foreign origin).

"One of the difficulties we have at the PMI is that we have a lot of very precarious families [...] therefore they face many difficulties other than the problems linked to their daily diet." (P12, HCP, PMI physician).

The lack of time and training (inconsistent training done on a voluntary basis) were also mentioned as barriers. It was also stated that the perpetual change in the child feeding recommendations confuses parents and impairs communication, since it induces the circulation of conflicting information, even among professionals. Socioeconomic insecurity was reported to impact communication on child feeding.

"It's supposed to be our role, but we don't necessarily have the training, support or the time." (P7, HCP, General practitioner)

\section{Needs of professionals to improve communication with parents}

Professionals mentioned that they needed "official documents" and nutrition training to improve their communication with parents to standardize the knowledge related to infant and young child feeding.

"There are a lot of different speeches that are not necessarily very serious and not very embarrassing, but I think that by standardizing the speeches, we would have more credit and it would be easier for parents." (P8, HCP, General practitioner)

Professionals working in PMls emphasized their need for more adapted media (in particular, a short document with many illustrations and few texts and/or in various languages). 
"In fact, we would need either adapted documents in several languages, or much simpler things. We really need things that are quick and simple to show to parents. And that's kind of what we're missing." (P20, CCP, PMI nurse)

\section{Needs of parents}

Professionals reported that parents are asking for information on feeding, especially CoF. They noted that some parents need very specific guidance from HCPs, while other parents prefer flexibility in the information they receive. Parents ask for details on the recommended quantities of food and milk as well as practical advice (e.g., how to introduce an allergen).

\section{2) Perceptions of the brochure}

\section{New recommendations}

Professionals were aware that it is now recommended to start CoF between four to six months of age to prevent allergies. However, when a mother was breastfeeding, professionals were more likely to recommend starting CoF at six months of age in accordance with the World Health Organization (WHO) recommendations (encouraging exclusive breastfeeding until six months of age).

"Sometimes breastfeeding mothers want to continue exclusive breastfeeding up to six months. In general, I am not really against it because the WHO recommends that. So, I don't have too many reasons to go against it especially if it's desired on their part." (P2, HCP, Pediatrician)

Recommending introducing all types of food between four to six months of age was still not grounded in practice among the interviewed professionals. Professionals were used to advising introducing proteins from six months of age, as suggested in the previous recommendations. Some doubts about the early introduction of allergens and proteins were expressed.

"Being able to introduce all the foods is the biggest novelty. We can introduce everything, taste more or less anything, in particular and at the same time, without respecting... waiting the six months." (P8, HCP, General practitioner)

"What's the point of wanting to absolutely start protein right away between four and six months? [...]. The info on the introduction of peanuts, which I used to do previously, but is it really scientifically validated? Because they don't all have the same indications about it between allergology organizations." (P5, HCP, Pediatrician)

According to the new brochure, pulses and whole grain starches can be introduced to children from four months of age. This recommendation sounded relatively new to professionals, but it appeared to be well 
accepted despite some doubts about their digestibility were raised. Some CCPs noticed that feeding practices in childcare centers do not meet this recommendation.

"I discovered that at four months you could give that: lentils and mashed beans. I did not know. It was complicated for me because the fiber and the lentil, bean, or chickpea skins have to be very well mixed. But I find it good, it's interesting." (P21, CCP, PMI nurse)

Most of the professionals knew that it was possible to alternate follow-on milk and full-fat cow milk after the child turned one years old. They found that this was a good option to propose to disadvantaged families. However, there was a tendency to emphasize follow-on formula to avoid iron deficiency. The purpose of this recommendation seemed to be less understood by CCPs.

"And I had to do it before because I know that you can give whole cow's milk instead of follow-on milk. [...] On the other hand, it is true that where I insisted, it was that it should not be exclusively cow's milk. They need a lot of iron and that is not covered by cow's milk." (P9, HCP, General practitioner)

"I think there is ambiguity, and we are not sure if we are completely marketing or if this follow-on milk really brings more to the children. And again, from one pediatrician to another, we can see that there are two schools, there are really those who switch to UHT milk without worry and others who are reluctant." (P14, CCP, professional working in a childcare center).

Professionals were familiar with non-recommended foods (e.g., plant-based alternatives to formula, sugar sweetened beverages and foods). Some of them asked for more explanation, especially regarding the new recommendation about avoiding chocolate until three years old.

Professionals mentioned that they particularly enjoyed one section of the brochure on baby-led weaning as they face an increasing number of questions about this topic and need more evidence-based information.

"As I read, I also thought about the baby-led weaning, I wondered if it would be covered when I saw that there was a little passage on it. It's true that sometimes it's not very common, but it so happens that there are parents who say they want to do the baby-led weaning when in fact, frankly, I have no knowledge of it. I do not know what to advise them, as it is really outside the framework of the recommendations that I've read." (P2, HCP, Pediatrician)

"Then, we have more and more questions about baby-led weaning. This is something I had never heard of... I have the feeling that a year ago we didn't talk about it, and in the last year we have talked about it a lot. There is a little insert on it, that's good." (P17, CCP, Childcare assistant)

\section{General impressions of the brochure}


Positive impressions of the brochure outweighed negative impressions (see Table 5). In fact, all 21 professionals expressed at least one positive impression, and overall, they seemed enthusiastic about the brochure (some of them wanted to use it forthwith).

\section{Table 5}

Summary of the general impressions about the brochure

\begin{tabular}{|ll|}
\hline Positive impressions & Negative impressions \\
\hline Complete and precise document $(\mathrm{n}=15)$ & $\begin{array}{l}\text { Long document (parents might consequently not read } \\
\text { it) }(\mathrm{n}=12)\end{array}$ \\
\hline $\begin{array}{l}\text { Positive tone (not judging/guilt-inducing) } \\
(\mathrm{n}=10)\end{array}$ & $\begin{array}{l}\text { Layout }(\mathrm{participants} \text { were provided with a draft (only } \\
\text { with text) }(\mathrm{n}=8)\end{array}$ \\
\hline $\begin{array}{l}\text { Agree on the topics order (from general to } \\
\text { age-adapted information) }(\mathrm{n}=9)\end{array}$ & Summary table is complex and difficult to read $(\mathrm{n}=7)$ \\
\hline $\begin{array}{l}\text { Global approach including advice on } \\
\text { screens, physical activity (etc.) and } \\
\text { parenting advice }(\mathrm{n}=9)\end{array}$ & $\begin{array}{l}\text { Some recommendations are still guilty-laden } \\
\text { (recommendations on breastfeeding, organic foods and } \\
\text { industrial foods) }(\mathrm{n}=3)\end{array}$ \\
\hline $\begin{array}{l}\text { Summary table is well done and useful } \\
(\mathrm{n}=7)\end{array}$ & $\begin{array}{l}\text { Unsuitable/lmproper advice about child motor } \\
\text { development }(\mathrm{n}=3)\end{array}$ \\
\hline
\end{tabular}

\section{Perceptions of the utility of the brochure in HCP and CCP practice}

HCPs considered the brochure as a supplement that could facilitate communication with parents. Using the brochure could help save time during consultations (parents could read the brochure at home and return to the next consultation with additional and more precise questions). Moreover, the brochure could enable HCPs to have a more systematic approach in their information delivery to parents about child feeding, and help HCPs update their knowledge of the new recommendations.

"I find that supports our speech by saying: "It's not just my personal opinion and what I personally believe. This is really what is recommended"." (P8, General practitioner)

"That [reading the brochure] clarifies the recommendations, so that's great. I am very happy with it. [...] I learned some things." (P9, HCP, General practitioner)

In PMIs, the brochure could be used only with a few parents because it is too long and complex for serving the most disadvantaged populations. CCPs generally stated that they would give the brochure to parents who have specific questions about infant and young child feeding. The brochure would help CCPs feel more legitimate and precise in giving advice to parents. 
"These are somewhat formal documents; we still say to ourselves that it was thoughtfully studied by professionals. It gives us legitimacy and technical consistency." (P14, CCP, Professional working in a childcare center)

\section{Suggestions to improve the brochure}

Most of the participants recommended making the brochure more entertaining (more pictures and less text) as they were provided with a preliminary version of the brochure with no illustrations. Participants suggested translating the brochure in different languages or to make one document with visual explanations and many pictures adapted to PMI populations. Participants also proposed making different detachable sheets adapted for each age range of the child to easily distill the information to parents. Including the brochure in the child health record booklet and adding more explanations and/or scientific references (e.g., why starting CoF between four to six months of age help prevent the development of allergies; why is it recommended to avoid salt until three years of age; scientific references to justify the introduction of gluten and nuts, etc.) were also popular suggestions.

"In fact, we should be able to cut down the number of items to give just the one that corresponds to the needs of the families in the moment. After that there is a need to put images so that we can adapt it to our families." (P20, CCP, PMI nurse)

Perceptions of the use that parents can have of the brochure

Professionals believe that the brochure is a comprehensive and useful written tool for parents and can serve as a reference for discussing child feeding with doctors. They believe that the brochure will be more useful for parents who are already invested in the topic of child feeding and that its usefulness will be more limited for parents of the most disadvantaged backgrounds. The brochure could encourage parents to change certain habits (e.g., to cook more homemade dishes).

\section{Discussion}

In this qualitative study, we interviewed French healthcare and childcare professionals who serve young children and their parents with the aim to explore their practices and needs when communicating with parents about child feeding from zero to three years of age. We also aimed to explore professionals' impressions regarding a brochure containing the newly updated child feeding recommendations and focused on understanding acceptance of the new nutritional recommendations. We decided to focus specifically on HCPs and CCPs in recognition of their central role in guiding and influencing parents in the early life of children (31).

The results of this study suggest that overall, the brochure meets professionals' needs. The paper format was well appreciated by professionals. This is in line with the results of a recent double survey regarding the perceived needs of French parents and pediatricians concerning information on $\mathrm{CoF}$, in which $59 \%$ of 
pediatricians and $42 \%$ of parents considered paper brochures to be an appropriate tool to spread information regarding CoF (27). Professionals indeed reported they would use the brochure as a medium to communicate with parents, except in serving PMI populations where a simpler and more colorful document was requested (it worth noting that the draft version of the brochure that was being tested at the time did not present any graphical adaptation yet). There are some differences in terms of communication practices between CCPs and HCPs, especially concerning the content of exchanges with parents. While CCPs tend to discuss more practical topics such as daily issues related to the diet of the child, HCPs tended to discuss more feeding-related topics. On average, pediatricians and GPs perceived the brochure as more useful in their practice than CCPs. Those dissimilarities in practices between CCPS and HCPs and their perceptions of the utility of the brochure could reflect the different roles of employment between these two professional categories. Specifically, while HCPs reported they could use the brochure in a systematic way with parents during consultations, CCPs would rather use it as an instrument to inform themselves, legitimize their knowledge on the subject, or to assuage the doubts of curious parents. Nevertheless, both types of professionals agreed that this brochure would enable them to update their knowledge about nutrition for children from zero to three years of age.

In PMI centers, the story is completely different from that in pediatricians' offices. In fact, the professionals dealing with more disadvantaged families expressed strain in having to use the brochure with their patients. Parents visiting PMI professionals are often immigrants or those of foreign origin who do not fluently speak or understand French; in those cases, an adapted tool with more pictures and images is required to facilitate communication. The lack of tools that account for the needs of those parents was previously noted in another study in which $35 \%$ of pediatricians thought that communication materials available to parents do not sufficiently consider the different economic and cultural situations of families (27). It was already demonstrated that public health campaigns focused on diet and nutrition struggle to reach those of modest means $(49,50)$. This aligns with data showing that chronic conditions such as obesity and diabetes are more prevalent within the lowest socioeconomic classes of society (51, 52). The challenges of involving a disadvantaged population in public health campaigns could exacerbate social health inequalities (53). To tackle this issue, the campaign regarding the new recommendations, which launched in September 2021, also included other mediums of communication, such as videos. These tools can overcome language barriers and may increase parents' capabilities to turn recommendations into practice by providing concrete advice and examples for feeding children. Disseminating health messages through HCPs and CCPs was also a means to efficiently reach all parents (including those who are disadvantaged), since a previous study has shown that HCPs and CCPs are the most influential sources of information to parents regardless of their financial status (31). In addition, in the near future, other tools are planned to be designed to specifically address the needs of disadvantaged populations as identified by professionals. Moreover, in France, the program MALIN (www.programme-malin.com) is now disseminated through the family allowance with the objective of promoting healthier food practices for children under the age of three who come from families in precarious situations (54). Disadvantaged families who meet the eligibility criteria (e.g., income) could be 
provided vouchers to buy baby food or groceries and given advice, to empower them to make better nutrition-related choices for themselves and for their children.

This study did not reveal important differences between the new recommendations and the advising practices of professionals (especially HCPs) but still pointed out particular advice given by professionals that could be updated and improved in light of the new recommendations, in particular with regard to the introduction of allergens and of all types of food between four to six months of age. Our results are in line with those of a study conducted in France in 2016, in which the interviewed general practitioners and pediatricians reported giving advice on child feeding in line with recommendations (55). For instance, in this study, professionals acknowledged that the right age for introducing complementary food was between four and six months of age and gave the appropriate advice to parents in $85.2 \%$ of cases. However, in the same study, the given advice was not in line with recommendations as was highlighted regarding the introduction of allergens and some foods. For example, $44.5 \%$ of professionals were advising parents to introduce gluten to their child after six months of age (55). Additionally, in the case of parental allergy history, there was a tendency to tell parents to postpone the introduction of some specific foods. Some of the professionals interviewed in our study also experienced doubts regarding the introduction of allergens. An uncertain opinion from a professional could create confusion regarding the time of introduction of complementary foods and could introduce non-compliance in parents due to reasons such as lack of confidence in the doctor and preference to follow advice from family or friends $(56,57)$. The uncertainty experienced by some professionals facing the newest recommendations underscores the time required for scientific, evidenced-based, knowledge to reach all the intended recipients. A consensus among professionals on child feeding recommendations could improve parental confidence to follow the given advice, but this remains a difficult objective to achieve. The French Public Health Agency has been moving in this direction with a communication campaign targeted toward professionals with the goal of sensitizing them to the new recommendations prior to the launch of the campaign targeted toward parents (August 2021).

The brochure produced by Public Health France is an official document that formalizes and standardizes the latest recommendations for feeding children from zero to three years of age. It is interesting to note that the brochure itself did not fulfill the HCPs' need for explaining some recommendations, since they expressed the need to verify some of the information themselves. As was the case in this study, GPs and pediatricians surveyed by Chouraqui et al. reported their need to obtain more information about certain infant feeding practices, more generally on specific pathology-related recommendations (such as the prevention of allergies, the age of gluten introduction, and the treatment of food allergies) as well as weaning and the introduction of foods according to the child's age (55). Interestingly, in our study, GPs and pediatricians also reported their need to obtain more information regarding the quantities of milk according to the child's age to answer parents' questions, which suggested that this recommendation about milk quantities still creates confusion. Professionals also needed more explanations regarding why some foods are not recommended to young children (e.g., certain types of fish, chocolate). French pediatricians surveyed by Banti et al. in 2015 to understand whether their practices followed official recommendations stated that frequent changes could be perceived as errors in the original or latest 
recommendations (58). This might reduce the level of trust in updated official documents, and consequently, the given advice may no longer align with the latest evidence. Clear explanations are requested to detail why recommendations had changed in comparison to the previous ones. In this case, scientific references are requested, especially by HCPs.

Our results showed that professionals believed that they have a role to play in the dissemination of the brochure. Indeed, the discourse of HCPs suggested that the brochure could help overcome some of their communication barriers. In fact, providing the brochure to parents would allow HCPs to save time during consultation (parents would have all the necessary information in the document so HCPs focus on talking about the most important topics and save time to answer questions) and to overcome the lack of practical advice (since the brochure contained practical advice such as recipes, which were appreciated by HCPs). In addition, using the brochure as a support to communicate with parents would help HCPs and CCPs provide more complete and systematic information about child feeding and bring more legitimacy to their communication with parents. In serving PMI populations, the main barrier to communication with parents was language. However, a written support with images and few words could facilitate communication with foreign or immigrant families. The development of other means of dissemination of information might be needed to foresee an inclusive strategy at every population level. The perspective of creating digital solutions has been discussed previously in the literature, but doubts still exist on how to deal with social disparities in terms of digital health (59).

Strengths and limitations must be analyzed when considering the results of our study. For the design of the study, we aimed to include unequal numbers in different professional categories. This decision was based on another recent study, as explained above, but this consideration should be taken when interpreting and generalizing the findings of our study. A potential bias could emerge when interpreting findings by giving undue prominence to views of certain professions (mostly GPs and pediatricians). Notwithstanding, during the analysis and presentation of the results, efforts were made to ensure that points at which views and perceptions differed across professional groups was explicitly stated. Additionally, as often happens with qualitative studies, social desirability bias could be a limitation; in fact, professionals might have had the instinct to say something just because it was perceived to be the "correct" answer according to their perception of their role. In addition, an effort was made to include a high number of doctors (GPs, pediatricians, PMI physicians) across a spread of different departments in France. In fact, this population is often difficult to involve in research studies due to work schedules that often cannot accommodate activities other than outpatient practice. Moreover, while we included a wide variety of professionals, other categories of HCPs and CCPs, such as midwives, could have been involved. Our inclusion method occurred mostly via social media, which yielded heterogeneity in terms of the age of the participants, which was not representative of the national population.

\section{Conclusions}

Early life is an important period for the development of healthy behaviors in children, especially regarding eating. Involving health professionals in a structured strategy of disseminating child feeding 
recommendations can be important given the high frequency of routine contact that they have with parents in their child's early years. This qualitative analysis conducted with health and childcare professionals allowed us to explore their practices and needs in terms of communication with parents on child feeding. Professionals reported that while communication with parents primarily occurs orally, they also often refer to other supports (e.g., pamphlets, online sources). Lack of time and language were major barriers, especially in PMI centers that are serving disadvantaged populations. Moreover, this study investigated whether professionals found the brochure developed by Santé publique France suitable to meet their needs, whether they could easily integrate the new recommendations when advising parents, and whether they considered that additional adaptations are needed. Our results showed that professionals generally welcomed the brochure, but this medium was still considered as a tool that was not well-suited for disadvantaged populations, for whom a different support that includes more visual representations should be developed. A strategy that entails the use of the same document by both parents and professionals has the advantage of harmonizing the information circulating between them. Professionals would feel more legitimate in advising parents with the help of a document enclosing recommendations supported by all the newest scientific evidence. Moreover, providing relevant and consistent information to parents could help reduce the flow of conflicting information and misinformation and ultimately increase parental support for adopting new recommendations in their child feeding practices. To reduce health inequalities, further actions are needed from the public health sector to more specifically address the disadvantaged population. In the long run, this may contribute to reducing social disparities in nutrition and health.

\section{Declarations}

\section{Ethics approval and consent to participate}

An informed consent was obtained from all the participants. Ethical approval $\left(n^{\circ} 21-788\right)$ for this study was obtained from the Institutional Review Board (IRB00003888, IORG0003254, FWA00005831) of the French Institute of Medical Research and Health. See the paragraph regarding "Ethical considerations" for more details. All methods were carried out in accordance with relevant guidelines and regulations.

\section{Consent for publication}

Not applicable.

\section{Availability of data and materials}

The datasets used and/or analyzed during the current study are available from the corresponding author on reasonable request. 


\section{Competing interests}

The authors declare that they have no competing interests.

\section{Funding}

The study was conducted as part of the project "Edulia-Bringing down barriers to children's healthy eating", which has received funding from the European Union's Horizon 2020 research and innovation program under the Marie Skłodowska-Curie grant agreement No 764985. This work was also supported by grants from the Conseil Régional Bourgogne, Franche-Comte (PARI grant) and the FEDER (European Funding for Regional Economic Development).

\section{Authors' contributions}

SDR was a major contributor in writing the manuscript, the study design and conception of the interview guide. SN, CRN, PD and CS contributed and validated the methodology and critically edited the interview guide. SDR and CRN finalized the interview guide. SDR and CRN analyzed the data, with constant feedback from the SN. All authors critically reviewed and commented on subsequent drafts of the manuscript and approved the final version.

\section{Acknowledgements}

The authors thank the professionals for their time and willingness to participate in the study. We also acknowledge Corinne Delamaire, Laurence Noirot and Anne-Juliette Serry (Santé publique France) for their advice when designing the interview guide and Courtney Dow (INSERM) for the translation of the verbatim.

\section{References}

1. Nicklaus S. The Role of Dietary Experience in the Development of Eating Behavior during the First Years of Life. Annals of nutrition \& metabolism. 2017;70(3):241-5.

2. Simeoni U, Bocquet A, Briend A, Chouraqui JP, Darmaun D, Dupont C, et al. L'origine précoce des maladies chroniques de l'adulte. Archives de Pédiatrie. 2016;23(5):443-6.

3. Blake-Lamb TL, Locks LM, Perkins ME, Woo Baidal JA, Cheng ER, Taveras EM. Interventions for Childhood Obesity in the First 1,000 Days A Systematic Review. American journal of preventive medicine. 2016;50(6):780-9.

4. Black RE, Victora CG, Walker SP, Bhutta ZA, Christian P, de Onis M, et al. Maternal and child undernutrition and overweight in low-income and middle-income countries. The Lancet. 2013;382(9890):427-51. 
5. Singh AS, Mulder C, Twisk JW, van Mechelen W, Chinapaw MJ. Tracking of childhood overweight into adulthood: a systematic review of the literature. Obesity reviews: an official journal of the International Association for the Study of Obesity. 2008;9(5):474-88.

6. Abdullah A, Wolfe R, Stoelwinder JU, de Courten M, Stevenson C, Walls HL, et al. The number of years lived with obesity and the risk of all-cause and cause-specific mortality. International journal of epidemiology. 2011;40(4):985-96.

7. Weihrauch-Blüher S, Schwarz P, Klusmann J-H. Childhood obesity: increased risk for cardiometabolic disease and cancer in adulthood. Metabolism. 2019;92:147-52.

8. Umer A, Kelley GA, Cottrell LE, Giacobbi P, Innes KE, Lilly CL. Childhood obesity and adult cardiovascular disease risk factors: a systematic review with meta-analysis. BMC Public Health. 2017;17(1):683.

9. Lioret S, Touvier M, Lafay L, Volatier J-L, Maire B. Dietary and Physical Activity Patterns in French Children Are Related to Overweight and Socioeconomic Status. The Journal of Nutrition. 2008;138(1):101-7.

10. Lobstein T, Baur L, Uauy R. Obesity in children and young people: a crisis in public health. Obesity reviews: an official journal of the International Association for the Study of Obesity. 2004;5 Suppl 1:4-104.

11. Bronfenbrenner $U$. The ecology of human development: Experiments in nature and design.: Cambridge, MA: Harvard University Press.; 1979.

12. Wood AC, Blissett JM, Brunstrom JM, Carnell S, Faith MS, Fisher JO, et al. Caregiver Influences on Eating Behaviors in Young Children: A Scientific Statement From the American Heart Association. Journal of the American Heart Association. 2020;9(10):e014520.

13. Hetherington MM. Understanding infant eating behaviour - Lessons learned from observation. Physiology \& Behavior. 2017;176:117-24.

14. Monnery-Patris S, Rigal N, Peteuil A, Chabanet C, Issanchou S. Development of a new questionnaire to assess the links between children's self-regulation of eating and related parental feeding practices. Appetite. 2019;138:174-83.

15. Brugaillères $P$, Chabanet $C$, Issanchou $S$, Schwartz $C$. Caloric compensation ability around the age of 1 year: Interplay with the caregiver-infant mealtime interaction and infant appetitive traits. Appetite. 2019;142:104382.

16. McNally J, Hugh-Jones S, Caton S, Vereijken C, Weenen H, Hetherington M. Communicating hunger and satiation in the first 2 years of life: a systematic review. Maternal \& Child Nutrition. 2016;12(2):205-28.

17. DiSantis KI, Hodges EA, Johnson SL, Fisher JO. The role of responsive feeding in overweight during infancy and toddlerhood: a systematic review. International Journal of Obesity. 2011;35(4):480-92.

18. Brugaillères $P$, Issanchou $S$, Nicklaus $S$, Chabanet $C$, Schwartz C. Caloric compensation in infants: developmental changes around the age of 1 year and associations with anthropometric measurements up to 2 years. The American journal of clinical nutrition. 2019;109(5):1344-52. 
19. Bell LK, Gardner C, Tian EJ, Cochet-Broch MO, Poelman AAM, Cox DN, et al. Supporting strategies for enhancing vegetable liking in the early years of life: an umbrella review of systematic reviews. The American journal of clinical nutrition. 2021;113(5):1282-300.

20. Haire-Joshu D, Tabak R. Preventing Obesity Across Generations: Evidence for Early Life Intervention. Annu Rev Public Health. 2016;37:253-71.

21. Smith JD, Fu E, Kobayashi MA. Prevention and Management of Childhood Obesity and Its Psychological and Health Comorbidities. Annu Rev Clin Psychol. 2020;16:351-78.

22. Schwartz C, Scholtens PA, Lalanne A, Weenen H, Nicklaus S. Development of healthy eating habits early in life. Review of recent evidence and selected guidelines. Appetite. 2011;57(3):796-807.

23. Fewtrell M, Bronsky J, Campoy C, Domellöf M, Embleton N, Fidler Mis N, et al. Complementary Feeding: A Position Paper by the European Society for Paediatric Gastroenterology, Hepatology, and Nutrition (ESPGHAN) Committee on Nutrition. Journal of pediatric gastroenterology and nutrition. 2017;64(1):119-32.

24. Norton JL, Raciti MM. Co-creating healthful eating behaviors with very young children: The impact of information overload on primary caregivers. Health Marketing Quarterly. 2017;34(1):18-34.

25. Chouraqui J-P, Tavoularis G, Emery Y, Francou A, Hébel P, Bocquet $M$, et al. The French national survey on food consumption of children under 3 years of age - Nutri-Bébé 2013: design, methodology, population sampling and feeding practices. Public Health Nutrition. 2017;21(3):50214.

26. Gildea A, Sloan S, Stewart M. Sources of feeding advice in the first year of life: who do parents value? Community practitioner: the journal of the Community Practitioners' \& Health Visitors' Association. 2009;82(3):27-31.

27. De Rosso S, Schwartz C, Ducrot P, Nicklaus S. The Perceptions and Needs of French Parents and Pediatricians Concerning Information on Complementary Feeding. Nutrients. 2021;13(7).

28. Nicklaus S, Remy E. Early Origins of Overeating: Tracking Between Early Food Habits and Later Eating Patterns. Current Obesity Reports. 2013;2(2):179-84.

29. ANSES. AVIS de l'Anses relatif à l'actualisation des repères alimentaires du PNNS - Jeunes enfants (0-3 ans). In: Agence nationale de sécurité sanitaire de l'alimentation dleedt, editor. 2019.

30. HCSP. AVIS relatif à la révision des repères alimentaires pour les enfants âgés de 0-36 mois et de 317 ans. 2020.

31. De Rosso S, Nicklaus S, Ducrot P, Schwartz C. Information seeking of French parents regarding infant and young child feeding: practices, needs and determinants. Public Health Nutrition. 2021:1-14.

32. Service-public.fr. Suivi médical de l'enfant: examens médicaux obligatoires 2020 [Available from: https://www.service-public.fr/particuliers/vosdroits/F967.

33. Bocquet A, Vidailhet M. Nutri-Bébé 2013 Study Part 2. How do French mothers feed their young children? Archives de pediatrie: organe officiel de la Societe francaise de pediatrie. 2015;22(10 Suppl 1):10s7-s9. 
34. Toomey E, Matvienko-Sikar K, Doherty E, Harrington J, Hayes CB, Heary C, et al. A collaborative approach to developing sustainable behaviour change interventions for childhood obesity prevention: Development of the Choosing Healthy Eating for Infant Health (CHErlsH) intervention and implementation strategy. British Journal of Health Psychology. 2020;25(2):275-304.

35. Stender SRS, Burghen GA, Mallare JT. The Role of Health Care Providers in the Prevention of Overweight and Type 2 Diabetes in Children and Adolescents. Diabetes Spectrum. 2005;18(4):240.

36. Boyle M, Lawrence S, Schwarte L, Samuels S, McCarthy WJ. Health Care Providers\&\#039; Perceived Role in Changing Environments to Promote Healthy Eating and Physical Activity: Baseline Findings From Health Care Providers Participating in the Healthy Eating, Active Communities Program. Pediatrics. 2009;123(Supplement 5):S293.

37. INEPS. La santé vient en mangeant et en bougeant. Le guide nutrition des enfants et ados pour tous les parents. 2004.

38. Thomas DR. A General Inductive Approach for Analyzing Qualitative Evaluation Data. American Journal of Evaluation. 2006;27(2):237-46.

39. Draper A, Swift JA. Qualitative research in nutrition and dietetics: data collection issues. Journal of Human Nutrition and Dietetics. 2011;24(1):3-12.

40. Whitehead LC. Methodological and ethical issues in Internet-mediated research in the field of health: An integrated review of the literature. Social Science \& Medicine. 2007;65(4):782-91.

41. Tong A, Sainsbury P, Craig J. Consolidated criteria for reporting qualitative research (COREQ): a 32item checklist for interviews and focus groups. International Journal for Quality in Health Care. 2007;19(6):349-57.

42. INSEE. Toujours plus d'habitants dans les unités urbaines [Available from: https://www.insee.fr/fr/statistiques/4806684.

43. INSEE. Taux de pauvreté selon l'âge du référent fiscal en 2018. Comparaisons régionales et départementales. [Available from: https://www.insee.fr/fr/statistiques/2012803.

44. Toomey E, Flannery C, Matvienko-Sikar K, Olander EK, Hayes C, Heffernan T, et al. Exploring healthcare professionals' views of the acceptability of delivering interventions to promote healthy infant feeding practices within primary care: a qualitative interview study. Public Health Nutrition. 2020;24(10):2889-99.

45. MacMillan Uribe AL, Woelky KR, Olson BH. Exploring Family-Medicine Providers' Perspectives on Group Care Visits for Maternal and Infant Nutrition Education. Journal of Nutrition Education and Behavior. 2019;51(4):409-18.

46. Sjunnestrand M, Nordin K, Eli K, Nowicka P, Ek A. Planting a seed - child health care nurses' perceptions of speaking to parents about overweight and obesity: a qualitative study within the STOP project. BMC Public Health. 2019;19(1):1494.

47. van der Maas JC, Corbee RJ, Kroese FM, de Ridder DTD, Vos RC, Nielen M, et al. Discussing overweight in children during a regular consultation in general practice: a qualitative study. BMC Family Practice. 2020;21(1):18. 
48. Braun V, Clarke V. Using thematic analysis in psychology. Qualitative Research in Psychology. 2006;3(2):77-101.

49. Régnier F, Masullo A. Une affaire de goût? Réception et mise en pratique des recommandations nutritionnelles. 2008.

50. Dhuot R. La genèse précoce des différences sociales dans les habitudes alimentaires 2018.

51. Tanaka T, Gjonça E, Gulliford MC. Income, wealth and risk of diabetes among older adults: cohort study using the English longitudinal study of ageing. European Journal of Public Health. 2012;22(3):310-7.

52. Bonaccio M, Bonanni AE, Di Castelnuovo A, De Lucia F, Donati MB, de Gaetano G, et al. Low income is associated with poor adherence to a Mediterranean diet and a higher prevalence of obesity: crosssectional results from the Moli-sani study. BMJ Open. 2012;2(6):e001685.

53. Barker D, Barker M, Fleming T, Lampl M. Developmental biology: Support mothers to secure future public health. Nature. 2013;504(7479):209-11.

54. Cavalli B, De Lauzon-Guillain B, Turck D, Beghin L, Bonhoure S, Deplanque D, et al. Challenges encountered for implementing a public health intervention: The ECAIL study Difficultés rencontrées pour la réalisation d'une recherche interventionnelle en santé publique: l'étude ECAIL. Cahiers de Nutrition et de Diététique. 2017;52(2):94-9.

55. Chouraqui J-P, Delmas B, Le Bris M, Bellaiche M, Jung C, Hanh T. Physicians advice, parental practice and adherence to doctor's advice: an original survey on infant feeding. BMC Pediatr. 2019;19(1):313-.

56. Moore AP, Milligan P, Goff LM. An online survey of knowledge of the weaning guidelines, advice from health visitors and other factors that influence weaning timing in UK mothers. Maternal \& Child Nutrition. 2014;10(3):410-21.

57. Tarrant RC, Younger KM, Sheridan-Pereira M, White MJ, Kearney JM. Factors associated with weaning practices in term infants: a prospective observational study in Ireland. The British journal of nutrition. 2010;104(10):1544-54.

58. Banti T, Carsin A, Chabrol B, Reynaud R, Fabre A. [Infant food diversification. Assessment of practices in relation to French recommendations in pediatricians and pediatric residents in southern France]. Archives de pediatrie: organe officiel de la Societe francaise de pediatrie. 2016;23(10):1018-27.

59. Régnier F. Social Appropriation of "Diet and Health" Information: From Public Health Campaigns to Digital Tools. Food and Health2019. p. 217-38.

\section{Supplementary Files}

This is a list of supplementary files associated with this preprint. Click to download.

- Additionalfile1.pdf 